\title{
Acceptability Level of Developed Material (SAI) Using ASSURE Model
}

\author{
Yolanda Reyes*, Jenina Oreste \\ College of Education, Bataan Peninsula State University, Balanga City Bataan, Philippines
}

How to cite this paper: Reyes,Y., \& Oreste, J. (2017). Acceptability Level of Developed Material (SAI) Using ASSURE Model. The Educational Review, USA, 1(3), 61-69. http://dx.doi.org/10.26855/er.2017.03.003

Corresponding author: Yolanda Reyes, $\mathrm{PhD}$, College of Education, Bataan Peninsula State University, Balanga City Bataan, Philippines.

\begin{abstract}
The researchers developed a computer based platform (Stand Alone Instruction) using the ASSURE model which incorporates Robert Gagne's events of instruction to assure effective use of media in instruction. The general problem of the study is to find out the acceptability level of the developed material using ASSURE model. Specifically, the acceptability level of the SAI is described as strongly acceptable in terms of content, clarity, appeal and originality. The enhanced developed material was further enhanced based on the recommendations and suggestions of the teacher and student respondents. The study is a creative research that uses mixed method which combines quantitative and qualitative techniques. The research study was carried out in two phases: The development of the SAI and the evaluation of the responses through the questionnaire which is adapted from Reyes and De Guia (2017) in order to determine the acceptability level of the SAI. The data were tabulated, analysed and presented using appropriate statistical tools like frequency distribution, percentage and weighted mean. It was recommended that similar studies be conducted in order to develop a culture of pedagogical innovations and academic research. The SAI developed in this may further be evaluated based from other perspective like that of ICT experts.
\end{abstract}

\section{Keywords}

ASSURE, Stand Alone Instruction, Assessment, Acceptability level

\section{Introduction}

The teachers of the 21st century are at the forefront meeting the challenges of globalization and coping with the learners who are called "digital natives". This is the time where information flourished and is made available in the worldwide web. With this, teachers are faced with the challenge of educating the tech savvy generation whose dependency on technology cannot be belittled. The need to retool the "digital immigrants" is of perennial concern of the Philippine educational system today. In the light of the needed competencies of the 21 st century teacher, the educational system has been undergoing a number of transformation. The recognition of the valuable power of multi-media and other technological advancement in teaching, the emergence of alternative instructional delivery mode, the internationalization of higher educational institutions, and the ASEAN integration and its impact to employment, competencies of graduates, and outcomes based curriculum are all parts of the new paradigm of innovative Philippine educational system.

With the pedagogical roles of the teachers, Ozalp (2006) stresses the importance of developing teachers' expertise not only on the content but also with strategies and techniques. It is expected that a teacher should be abreast with advancement on these matter to cater students' multi-intelligences. Ensuring that instruction is designed, developed and produced 
in a systematic manner that will produce efficient and effective learning. Proper learning materials must be prepared and used for meaningful learning outcomes.

As Yusuf (2005) states, the field of education has been affected by ICTs, which have undoubtedly affected teaching, learning and research. Teachers are now expected to cope up with the skills of the 21 st century learners because the learners of the 21 st century are no longer passive but rather engaged. While the acquisition of learning takes place anywhere and comes in different modes, teachers are expected to guard the students on the competencies that they need to acquire. Finally, there is a need to keep abreast with the new discoveries and developments that may be useful in teaching.

Stand Alone Instruction (SAI) is an innovative audio-visual instructional material. This is used by contemporary teachers in other countries as a remediation for students who encounter difficulty in coping with lessons in Mathematics. The instruction provides students the whole lesson that includes all teaching-learning interactions from a day's objective. SAI has been used by teachers along with other computer aided instructions to cater the needs of the students and boost their interest in learning subject areas.

With this, the researchers find interest in coming up with a Stand Alone Instruction in Educational Technology class for college students. The study is anchored on the Instructional Design theory of Reigeluth (1999) which offers explicit guidance on how to better help people learn and develop. In the process of construction, ASSURE instructional design model was used which states that it is extremely learner-centered using cognitive theories of learning as its foundation. (Smaldino, Russell, Heinrich, \& Molenda, 1999). The directions of ASSURE Model are characteristic features of learners, getting stated objectives and selecting the best media and materials for the instruction program. This model includes 6 phases: Analyze the learner, State objectives, Select media, Utilize, Require students' participation, Evaluate and Revise. The development of SAI is deemed to strengthen the students' knowledge which is presented as a deviation from the usual printed modules provided. Thus, this idea encourages us to discover the best teaching-learning techniques to ensure an inclusive and learner-centered education (DepEd Order no.39, s.2016). SAI will also the students another innovative and easy way of understanding their lessons. Aside from this instruction fosters independent learning, this also provides them equal opportunity in education as stated in the DepEd's goal - 'no one should be left behind.

Learning in well-designed digital contexts can lead to the replication in the real world of behaviors successful in simulated environments. Believing that one of the major criticisms of instruction today is the low rate of transfer generated by conventional instruction (Murray 1997).

As mentioned by Gulbahar and Alper 2011, their study indicated that students' preferred online learning for its potential in providing a clear and coherent structure of the learning material in supporting self-regulated learning. However, students preferred face-to-face learning for communication purposes in which a shared understanding has to be derived or in which interpersonal relations are to be established.

For the clarity of the developed material, the acoustic integrity of the music's electromechanical capturing and transmission should be noted. This is influenced by such technical considerations as the type of microphones, speakers, recorders, mixers, processors, disc drives and players that pick up, store, manipulate, and reproduce the musical content (Orlik, 1994).

Battalio (2009) conducted a study in order to determine the extent to which student learning styles are associated with success in online learning environments, particularly when controlling the amount of collaboration available to students. As concluded by the researcher, the results of this study have shown significant associations between students' learning styles and success in distance education and offer insight into the relationship between learning style and mode of delivery. 
Thus, Gulbahar (2005) and Whiteley (2007) point out the virtual world of learning, together with the tools and technologies implemented, has definitely changed the method of delivery, but it has not changed the ultimate goal of learning. These studies signify that online learning environments should be designed and implemented to accommodate individual differences and further studies should be done to clarify the phenomenon.

Since technology has offered our students a different environment which is very stimulating, also it has provided our students with an opportunity to learn and relearn the previous lessons at his or her own pace. Providing students with an option on how they will cope up with what they have missed with the help of technology, the quality of education will never be at par.

In the era of technology playing a phenomenal role in the teaching learning process, there are variety of learning materials, methods and techniques available. One among these is Stand Alone Instruction which may be designed using ASSURE model. The Stand Alone Instruction creates the avenue for independent learning. The package tend to deploy the media in a creative and productive way and to respond constructively on the technological and social change. The development of the package involves 6 phases: Analyze the learner, State objectives, Select media, Utilize, Require students' participation, Evaluate and Revise.

The development of a Stand Alone Instruction to provide a stimulating environment/experience for students who were not able to attend the class or those who failed to understand the concept discussed by the teacher due to some factors like students are not feeling well. Also, to provide an acceptable learning material for the 21st century learners.

This study has a two-fold general objective: To develop a Stand Alone Instruction for students who need back up for independent learning and to determine level of acceptability of the developed instructional material.

\subsection{Statement of the Problem}

The general problem of the study is "What is the acceptability level of the developed Computer Based instructional material using ASSURE model?

Specifically, this research will attempt to answer these questions:

How may the developed material (SA) be developed following the ASSURE model:

a. analysis of the learner

b. state the objectives

c. select media and materials

d. utilization

e. required students participation

f. evaluate?

How may the developed material be further enhanced using the recommendations and suggestions of the experts and student respondents?

How may the acceptability level of the SAI be described by the different fields of specialization of Pre service education in terms of:

a. content;

b. clarity;

c. appeal to the target users and ;

d. originality?

\section{Methodology}

The first phase of the study includes the procedure in the development of the SAI for Educational Technology (Educ 109) 
class and its evaluation. The considerations in the organization, construction and design of the stand-alone instruction supported by the instructional design model are briefly discussed. Then the second phase of the study presents the research population and sampling, research instrumentation, the detailed method of development and evaluation of the SAI and statistical treatment.

\subsection{Methods and Techniques of Research}

The study is a creative research that uses mixed method. Mixed method is a type of research method that combines quantitative and qualitative techniques. The research is carried out in two phases: The development of the SAI and evaluation of the responses through the questionnaire in order to determine acceptability level of the SAI.

\subsection{Population and Sample of the Study}

The respondents are the 2nd year students taking Education course. There were 156 student respondents from the different fields of specialization in the College of Education. The Slovin formula is used to get the number of respondents per major. The researchers asked the respondents to view the Stand Alone Instruction in a conducive classroom (EdTech lab). The researchers requested the respondents to evaluate the acceptability of the CAI in terms of acceptability of the content, clarity, appeal and originality.

\subsection{Research Procedure}

Phase 1. Development of the stand alone instruction.

Stage 1. Analyze the learners. The target students consist of 156, mostly 18 years old, second year BSE who finished basic computer during their first year in college. The students are already proficient in the basic computer skills needed to understand the instructional material. Most have their own computer at home but do not have high-speed Internet access. They are mostly visual learners.

Stage 2. State objectives.

The development of SAI is based on the sequence of lessons found on the syllabus. A detailed lesson plan is prepared to formulate objectives for each lesson. There are selected lessons which become part of the SAI project.

Stage 3. Select media and materials.

Methods

1) The presentation takes at least 15 minutes, covering the complete parts of a learning plan. The lesson is presented in a manner of actual teaching procedure. 2) The presentation shows some videos about the topic for the day. Students' participation are ensured by the aid of anchored learning method. 3) Students in the presentation are asked questions to fully understand what transpired during the discussion. Activities are given to apply the skills that students need to achieve. Extra time is allotted for the preparation of the activity and output presentation.

Media

Computer, video clips, photos and audio is used to complete the presentation of lessons. The internet is considered in the preparation of the presentation like the www.texttospeech.com where recorded dialogues is done. PowerPoint is also used to prepare the design and appearance of the lessons and later convert it into video presentation for stand-alone instruction.

Materials

Textbooks on educational technology and video clips available on line are used for references.

Stage 4. Utilization. 
Preview the materials: The Stand Alone Instruction is viewed for evaluation. It is viewed for less than 15 minutes per lesson. The teacher ensures that there is a computer and LCD projector or a new model of TV set where files from the flash drive can be viewed. The teacher has to make sure that all these necessary devices are functioning properly which will aid in the effectiveness of the delivery of the lesson. Students maintain orderliness while asked to view the presentation.

Stage 5. Required students' participation. Students' participation on the evaluation of the stand alone instruction is done by giving them quiz and also by asking them to give comments and suggestions to further improve the material.

Stage 6. Edit and revise.

With the recommendation mentioned by the respondents, the developed material was revised. Revisions are made after deliberation and made necessary changes on the story board followed by the revisions made on the presentation and finally convert the final presentation into video.

Phase 2. Evaluation of the SAI.

Stage 1. Adaption/modification and validation of research questionnaire.

Stage 2. Students viewing of the lessons in Educational Technology.

Stage 3. Floating and retrieval of questionnaire.

Stage 4. Tabulated and analyze results.

\subsection{Data Gathering Procedures}

The researchers adapted a questionnaire by Reyes and De Guia (2017) that is used for evaluating the project. Afterwards, student-respondents who are involved in the process of evaluation of the SAI were determined through the use of Slovin's formula.

During the evaluation process, respondents were given close-ended questionnaires where they have to choose among the 4 points of the Likert scale. Right after administering the questionnaire for the student respondents, obtained data were tabulated, analyzed and presented for the realization of the purpose of this study.

Data Processing and Statistical Treatment

To determine the quality of the developed material the researchers will use the weighted mean formula:

$\mathrm{WM}=4 \mathrm{f}+3 \mathrm{f}+2 \mathrm{f}+1 \mathrm{f}$

$\mathrm{N} \quad \mathrm{N}$

Where:

$\mathrm{WM}=$ weighted mean

$\mathrm{F}=$ frequency of responses

$\mathrm{N}=$ respondents

The acceptability of the stand-alone instruction will be interpreted using the following four -level Likert scale Table 1:

Table 1. Four -level Likert scale.

\begin{tabular}{ccc}
\hline Print score & Range interval & Descriptive Rating \\
\hline 4 & $3.50-4.00$ & Strongly Acceptable (SA) \\
3 & $2.50-3.49$ & Acceptable (A) \\
1 & $1.50-2.49$ & Unacceptable (U) \\
& $1.00-1.49$ & Strongly unacceptable (SU) \\
\hline
\end{tabular}




\section{Findings and Discussion}

\subsection{Presentation and Analysis of the Data}

After the data were statistically treated, the following are the results.

Evaluation of the content of the SAI.

Table 2 shows the computed weighted mean per major and their descriptive values as follow: English with weighted mean of 3.66 (Strongly Acceptable) is the highest mean among the 7 majors, Biological Science and Filipino tied with 3.62 (Strongly Acceptable) come in next, meanwhile Mathematics has a relative score of 3.63 (Strongly Acceptable). On the other hand, MAPEH with a relatively close mean score with Physical Science 3.56 (Strongly Acceptable), 3.54 (Strongly Acceptable) respectively follow. Social Studies, with a mean score of 3.43 (Acceptable) comes in last.

Table 2. Weighted mean on the acceptability level of content.

\begin{tabular}{cccccccc}
\hline & Bio & English & Filipino & Math & MAPEH & PS & SS \\
\hline 1. & 3.88 & 4.00 & 3.81 & 3.96 & 3.76 & 3.84 & 3.73 \\
2. & 3.44 & 3.62 & 3.57 & 3.70 & 3.41 & 3.68 & 3.18 \\
3. & 3.63 & 3.48 & 3.52 & 3.52 & 3.47 & 3.47 & 3.55 \\
4. & 3.63 & 3.62 & 3.62 & 3.52 & 3.59 & 3.26 & 3.45 \\
5. & 3.63 & 3.57 & 3.67 & 3.43 & 3.59 & 3.42 & 3.23 \\
CM & 3.64 & 3.66 & 3.64 & 3.63 & 3.56 & 3.54 & 3.43 \\
\hline
\end{tabular}

Table 3. Weighted mean on the acceptability level of clarity.

\begin{tabular}{ccccccccc}
\hline & Bio & English & Filipino & Math & MAPEH & PS & SS \\
\hline 1. & 3.75 & 3.95 & 3.95 & 3.96 & 3.88 & 3.84 & 3.73 \\
2. & 3.88 & 3.76 & 3.62 & 3.78 & 3.88 & 3.84 & 3.77 \\
3. & 3.75 & 3.76 & 3.48 & 3.48 & 3.71 & 3.53 & 3.50 \\
4. & 3.75 & 3.62 & 3.67 & 3.52 & 3.68 & 3.58 & 3.50 \\
5. & 3.63 & 3.81 & 2.71 & 3.61 & 3.56 & 3.74 & 3.50 \\
CM & 3.75 & 3.78 & 3.49 & 3.67 & 3.74 & 3.71 & 3.60 \\
\hline
\end{tabular}

Table 3 shows the computed weighted mean of the SAI in terms of clarity. English got the highest weighted mean which is 3.78 which means that its descriptive value is 'Strongly Acceptable. Biological Science has 3.75, MAPEH has 3.74, Physical Science has 3.71, Mathematics has 3.67, and Social Science with 3.60 which all weighted means are also 'Strongly Acceptable'. Filipino's weighted mean is 3.49, though the lowest has an Acceptable descriptive value.

Table 4 shows the computed weighted mean of the SAI in terms of appeal. Social Studies got the highest weighted mean of 3.58 which has a descriptive value of Strongly Acceptable. Biological Science and English are in the 'Strongly Acceptable' descriptive value in which Biological Science and English have mean scores of 3.51 and 3.54 respectively. Filipino, Mathematics, and MAPEH's computed weighted means are relatively close for Filipino got 3.41, Math is 3.43, and MAPEH is 3.44. This shows that their computed weighted means have a descriptive value of 
'Acceptable'. On the other hand, Physical Science got the lowest computed weighted mean which is 3.38 but still has a descriptive value of 'Acceptable'.

Table 4. Weighted mean on the acceptability level of appeal.

\begin{tabular}{|c|c|c|c|c|c|c|c|}
\hline & Bio & English & Filipino & Math & MAPEH & PS & $\mathrm{SS}$ \\
\hline 1. & 3.50 & 3.62 & 3.38 & 3.48 & 3.56 & 3.47 & 3.82 \\
\hline 2. & 3.25 & 3.57 & 3.43 & 3.43 & 3.38 & 3.53 & 3.64 \\
\hline 3. & 3.56 & 3.76 & 3.52 & 3.30 & 3.62 & 3.16 & 3.50 \\
\hline 4. & 3.56 & 3.29 & 3.33 & 3.39 & 3.35 & 3.26 & 3.41 \\
\hline 5. & 3.69 & 3.48 & 3.38 & 3.52 & 3.29 & 3.47 & 3.55 \\
\hline $\mathrm{CM}$ & 3.51 & 3.54 & 3.41 & 3.43 & 3.44 & 3.38 & 3.58 \\
\hline
\end{tabular}

Table 5 shows the computed weighted mean per major and their descriptive value are as follow: Filipino with weighted mean of 3.66 (Strongly Acceptable) is the highest mean among the 7 majors, English with 3.59 (Strongly Acceptable) is the second, meanwhile Biological Science has a mean score of 3.56 (Strongly Acceptable) which is relatively close to the mean score obtained by Physical Science which is 3.51 (Strongly Acceptable), meanwhile MAPEH, Social Studies, and Mathematics have relatively close mean scores of 3.47, 3.46, and 3.44 respectively (Acceptable).

Table 5. Weighted mean on the acceptability level of originality.

\begin{tabular}{cccccccc}
\hline & Bio & English & Filipino & Math & MAPEH & PS & SS \\
\hline 1. & 3.69 & 3.57 & 3.71 & 3.48 & 3.50 & 3.68 & 3.50 \\
2. & 3.50 & 3.62 & 3.76 & 3.48 & 3.47 & 3.32 & 3.55 \\
3. & 3.63 & 3.76 & 3.38 & 3.65 & 3.50 & 3.47 & 3.50 \\
4. & 3.63 & 3.57 & 3.90 & 3.43 & 3.47 & 3.37 & 3.42 \\
5. & 3.38 & 3.43 & 3.52 & 3.17 & 3.47 & 3.51 & 3.45 \\
CM & 3.56 & 3.59 & 3.66 & 3.44 & & 3.46 \\
\hline
\end{tabular}

Table 6 shows the computed mean per major with their descriptive value; in terms of the acceptability level of the CAI based upon its content, clarity, appeal, and originality. The weighted mean per major and their descriptive value are as follow: English with weighted mean of 3.64 (Strongly Acceptable) is the highest mean among the 7 majors, Biological Science with 3.62 (Strongly Acceptable) is the second, meanwhile Filipino and MAPEH with tied score of 3.55 (Strongly Acceptable) are relatively close to the mean scores obtained by Math and Physical Science which is 3.54 (Strongly Acceptable), meanwhile Social Studies has the lowest mean of 3.52 (Strongly Acceptable). Thus, with a general mean of 3.57 which has the descriptive value Strongly Acceptable, the result illustrates that the CAI in terms of its content, clarity, appeal, and originality, is within the conventional level of students as far as their knowledge is concerned. 
Table 6. Composite mean.

\begin{tabular}{cccccccccc}
\hline & Bio & English & Filipino & Math & MAPEH & PS & SS & \\
\hline A & 3.64 & 3.66 & 3.64 & 3.63 & 3.56 & 3.54 & 3.43 & 3.59 \\
B & 3.75 & 3.78 & 3.49 & 3.67 & 3.74 & 3.71 & 3.60 & 3.68 \\
C & 3.51 & 3.54 & 3.41 & 3.43 & 3.44 & 3.38 & 3.58 & 3.47 \\
D & 3.56 & 3.59 & 3.66 & 3.44 & 3.47 & 3.51 & 3.46 & 3.53 \\
Total & 3.62 & 3.64 & 3.55 & 3.54 & 3.55 & 3.54 & 3.52 & 3.48 \\
Grand Mean & & & & & & & & & \\
\hline
\end{tabular}

As to content, Social studies and Physical Science major students both agreed that the SAI project is well-presented. Other majors shared the same observation that it is a good way in presenting lesson. Their common suggestions to improve its content are to add more varied and practical activities and more students' responses.

As to clarity, the common comments of the different majors are that it is clearly presented and understandable. They observed that the teacher in the CBI Project was able to deliver the lesson clearly. However, most of them recommended that more examples should be given to better clarify ideas.

As to appeal to target users, Math, MAPEH, Filipino and English shared the same comment which is that the SAI Project captures the students' interest and attention. However, most of them observed that the voice of the characters or the audio used is monotonous. Their suggestion with regards to this is that it should be made livelier and should have varying intonations.

As to originality, Math, Biological Science, Filipino and Social Studies shared the same observation that the SAI Project is a new and creative way or approach of presenting the lesson and that it is appropriate for 21 st century education.

Their overall impression towards this Stand-alone instruction is that it is a nice, very good and impressive way of presenting a lesson. They also come up to the conclusion that it is a promising mode of instruction.

\section{Recommendations and Conclusion}

Through the different insights gained during the conceptualization, conduct, and finalization of this study, the researchers consider more possibilities relevant to this research. Hence the following are conclusion and recommendations of the respondents:

\subsection{Recommendations}

1) Similar studies can be conducted with other courses or content areas of the different programs offered in Bataan Peninsula State University in order to develop a culture of pedagogical innovations and academic research.

2) Other components of SAI such as effectiveness and usability can be explored by other researchers.

3) As recommended by most of the respondents in this study, the SAI must provide more real world activities and personalized or recorded audio

4) The SAI developed in this study may further be evaluated based from other perspective like that of teachers and ICT experts.

5) Other application can be used with the construction of technology based instruction.

\subsection{Conclusion}


The acceptability level of the SAI, in terms of content, falls under the descriptive value Strongly Acceptable which implies a positive impression from the point of view of student-respondents of the IM from the different fields of specialization.

The acceptability level of the SAI, in terms of clarity, falls under the descriptive value Strongly Acceptable which implies that the organization of ideas and the clarity of the presentation of concepts are seen as one of the positive features of the SAI. Remarkably, compared with other features of the SAI, clarity receives the highest level of acceptability.

The acceptability level of the SAI, in terms of appeal, falls under the descriptive value Strongly Acceptable which implies that this feature of the SAI received a positive reaction from the respondents but not enough to reach a higher mean score.

The acceptability level of the SAI, in terms of originality, falls under the descriptive value Strongly Acceptable which implies a positive impression from the point of view of student-respondents of the IM.

The mean score that the SAI obtained from the evaluation conducted by the second year students fall under the descriptive value of 'Strongly Acceptable'. Though in the results of the evaluation, mean scores obtained by the different major, differs but in only few points from the other thus generally categorized still as 'Strongly Acceptable'. There may be differences with their mean scores, but the different fields of specialization viewed the project positively.

Furthermore, this SAI may be a starting point for IM developers to come up with IM that matches the needs and interests of the learners. Thus, future researchers may want to modify some parts of the project to make it more appealing and interesting by adding varied examples. Meanwhile, the SAI, given the 'Strongly Acceptable' descriptive value has the potential to be an alternative solution for filling the gap in the teaching-learning process.

\section{References}

Reyes, Y., \& De Guia. (2017). Development of English Worktext in English 101. International Journal of Science and Research, 6(10), 746. Ozalp. (2006). A Study on Implementing the Technique of Caricature in Science and Environmental Education. Unpublished Master Thesis . Celal Bayar University, Graduate School of Natural and Applied Sciences, Manisa.

Yusuf, M. O. (2005). Information and Communication Education: Analyzing the Nigerian National Policy for Information Technology. International Education Journal, 6(3), 316-321.

Reigeluth, C. M. (1999). Instructional Design Theories and Models, A New Paradigm of Instructional Theory Volume II. Lawrence Erlbaum Associates, Inc.

Heinich, R., Molenda, M., Russell, J., \& Smaldino, S. (1999). Instructional Media and Technologies for Learning. (6th ed.) Upper Saddle River, NJ: Prince Hall. EDIT 6180 University of Georgia..

Murray J. (1997). Hamlet on the Holodeck. Cambridge, Mass.: MIT Press. Accessed February 23, 2016 http://www.educause.edu/research-and-publications/books/educating-net-generation/planning-neomillennial-learning-styles-implications-inv estments-tech.

Gulbahar, Y. (2005). Learning Preferences and Learning Styles of Online Adult Learners. Distance Education Center, Ankara University, Golbaş1, 06830 Ankara, Turkey.

Orlik, P. B. (1994). Electronic Media Criticism, Third Edition. Focal Press, Master e-book.

Battalio, J. (2009). Success in Distance Education: Do Learning Styles and Multiple Formats Matter? The American Journal of Distance Education, 23: 71-87.

Whiteley, T. R. (2007) Integrating the Technological Resources of the Online Learning Environment with the Vak Learning-Styles Model to Foster Student Learning. In AMA Winter Educator's Conference Proceedings by American Marketing Association, 1-9. 